\title{
Grain Growth Characteristics of Hydrothermally Prepared Yttria Stabilized Zirconia Nanocrystals during Calcination
}

\author{
Li Fei ${ }^{1}, \quad$ Li Yanhuai ${ }^{1}, \quad$ Song Zhongxiao', $\quad$ Xu Kewei ${ }^{1}, \quad$ Ma Dayan', Gao Bo ${ }^{2}, \quad$ Cui \\ Hong $^{2}$
}

${ }^{1}$ State Key Laboratory for Mechanical Behavior of Materials, Xi'an Jiaotong University, Xi'an 710049, China; ${ }^{2}$ Engineering Research Center for Nanomaterial \& Coating, Xi'an Aerospace Composites Research Institute, Xi'an 710025, China

\begin{abstract}
Yttria stabilized zirconia (YSZ) nanocrystals were prepared by hydrothermal synthesis and were calcinated at different temperatures and with different isothermal hold time. X-ray diffraction via whole powder pattern modeling approach was used to study the grain growth as well as the evolution of grain size distribution of YSZ nanocrystals. Results show that YSZ nanocrystals start to grow along with the grain size distribution broadening at about $300{ }^{\circ} \mathrm{C}$. The grain growth rate and the grain size distribution of YSZ nanocrystals are dependent on the calcination temperature and the isothermal hold time. The grain growth exponent and the active energy of grain growth were calculated. Grain rotation induced grain coalescence is suggested as the predominant way of grain growth of YSZ nanocrystals.
\end{abstract}

Key words: YSZ nanocrystals; grain growth; grain size distribution; grain rotation induced grain coalescence

Yttria stabilized zirconia (YSZ) is a well known material which is frequently used as structural ceramics ${ }^{[1]}$, medical implants $^{[2]}$, sensors ${ }^{[3]}$, thermal barrier coatings ${ }^{[4,5]}$ and so on. It is known that nanocrystalline YSZ (nYSZ) exhibits higher strength, higher fracture toughness, higher iron conductivity as well as lower sintering temperature ${ }^{[6-8]}$ as compared to the coarse-grained YSZ. The deviation of properties of nYSZ is attributed to its small grain size and thus the presence of excess grain boundaries in it; consequently, grain size is an important factor in determining the properties of $\mathrm{nYSZ}^{[9]}$.

Fabrication of nYSZ includes the synthesis of appropriate YSZ nanocrystals and the sintering of green body compacted from YSZ nanocrystals ${ }^{[10]}$. However, nanocrystals tend to grow up fast even when being sintered at low temperature because of the high specific surface and thus the high driving force for sintering. Provided it can be controlled, grain growth will lead to the deterioration of properties of final counterparts ${ }^{[10-12]}$. Moreover, nanocrystals are generally heterogeneous with broad or narrow grain size distribution depending on their synthesis route. Grain size distribution is another important factor in determining the properties of nYSZ because it influences the homogeneity of properties ${ }^{[13,14]}$. Thus, for finely turning the microstructure and the properties of nYSZ, it is of technological importance to understand the grain growth characteristics of YSZ nanocrystals during sintering.

Transmission electron microscopy (TEM) and X-ray line profile analysis (XLPA) are commonly used to study the grain size and the grain size distribution of nanocrystals. Compared with TEM, XLPA is more convenient because it has inherently broad statistical basis ${ }^{[15]}$. Among approaches of XLPA used to analyze the grain size of nanocrystals, Whole Powder Pattern Modeling (WPPM) approach uses physical models of microstructure (e.g. domain size, shape, defects) to describe the line profiles of X-ray diffraction (XRD) without requiring a priori assumption on the shape of XRD line profiles ${ }^{[16-18]}$; thus, it provides a direct relation 
between the microstructural parameters of nanocrystal and the XRD line profiles. In addition, the grain size distribution of nanocrystals can be directly obtained through WPPM analysis ${ }^{[19]}$.

In the present paper, YSZ cubic nanocrystals were prepared by hydrothermal synthesis. The hydrothermal synthesis technique is used since it can prepare YSZ nanocrystals with fine grain size and narrow grain size distribution at low temperature ${ }^{[20,21]}$. The as-prepared YSZ nanocrystals were calcinated at different temperatures and with different isothermal hold time. XRD via WPPM approach was used to study the grain size and the evolution of grain size distribution of YSZ nanocrystals. The purpose of this paper is to study the grain growth characteristics of hydrothermally prepared YSZ nanocrystals during sintering.

\section{Experiment}

Hydroxides gel was co-precipitated from $\mathrm{ZrOCl}_{2} \cdot 8 \mathrm{H}_{2} \mathrm{O}$ and $\mathrm{YCl}_{3}$ mixed aqueous solution with $\mathrm{NH}_{3} \cdot \mathrm{H}_{2} \mathrm{O}$; the ratio of $\mathrm{Y}_{2} \mathrm{O}_{3}$ to $\mathrm{Y}_{2} \mathrm{O}_{3}+\mathrm{ZrO}_{2}$ in solution was $8 \mathrm{~mol} \%$ to obtain cubic nanocrystals. The gel was aged for $24 \mathrm{~h}$ and then was hydrothermally treated in an autoclave. The autoclave was maintained at $250^{\circ} \mathrm{C}$ for $2 \mathrm{~h}$ with autogenous pressure of 2 $\mathrm{MPa}$ and was cooled naturally to room temperature. The product was washed with deionized water and alcohol to remove $\mathrm{Cl}^{-}$ions. The washed product was dried at $120^{\circ} \mathrm{C}$ in air for $10 \mathrm{~h}$.

Non-isothermal sintering of the as-dried nanocrystals was conducted at temperatures from $300{ }^{\circ} \mathrm{C}$ to $1200{ }^{\circ} \mathrm{C}$. When reaching the given temperature, the sample was cooled down quickly by taking it out of the muffle furnace. Isothermal sintering of the as-dried nanocrystals was conducted at temperatures from $300{ }^{\circ} \mathrm{C}$ to $1200{ }^{\circ} \mathrm{C}$ with different isothermal hold time of 60,180 and $300 \mathrm{~min}$ at each calcination temperature. The heating rate of experiments was $2^{\circ} \mathrm{C} / \mathrm{min}$.

High resolution transmission electron microscopy (HRTEM) images were taken with JEOL 2100F. XRD patterns were recorded using a powder diffractometer (Advanced D8, Bruker) with nickel-filtered and $\mathrm{Cu} \mathrm{K \alpha}$ radiation; intensities were obtained in the $2 \theta$ range $20^{\circ} \sim 80^{\circ}$ with a step rate of $0.02^{\circ} / 2 \mathrm{~s}$ per point. WPPM analysis of XRD line profiles was conducted using program PM2K ${ }^{[22]}$.

\section{Results and Discussion}

\subsection{WPPM analysis}

Since the WPPM approach uses physical model of microstructure to describe the XRD profiles, factors which cause the broadening of XRD profiles, such as instrumental width of diffractometer, lattice defects, grain size and grain shape of nanocrystals, should be determined before analysis ${ }^{[23]}$. In the present study of WPPM analysis, the instrumental width was represented by Caglioti formula whose parameters were evaluated from the experimental XRD profiles of standard Si (NIST SRM 640c) ${ }^{[24]}$. Grain shape of YSZ nanocrystals was determined from HRTEM images shown in Fig.1. From Fig.1, it can be seen that nanocrystals are well crystallized with tetragonal shape. The grain size of nanocrystals is about 10 and $20 \mathrm{~nm}$. The lattice planes of nanocrystals are sharp and straight, which implies the presence of low level lattice defects. Thus, YSZ nanocrystals can be treated as defects free and factor that caused line broadening of XRD patterns is the small grain size of nanocrystals.

Lognormal distribution function, which is frequently used to describe the size distribution of particles, is chosen for describing the grain size distribution in WPPM analysis. Lognormal function is a positively skewed unimodal distribution with two parameters: lognormal mean $(u)$ and variance $(\sigma)$; by refining the two parameters, the arithmetic mean grain size $(D)$ of nanocrystals can be obtained in terms of $u$ and $\sigma$ as: ${ }^{[25]}$

$$
D=\mathrm{e}^{\left(\mu+\frac{\sigma^{2}}{2}\right)}
$$

An example of WPPM analysis result is plotted in Fig.2. The residuals line (bottom of Fig.2) is flat, which means good agreement between the experimental data and the data calculated by WPPM approach.

\subsection{Grain growth of non-isothermal sintering}

Fig.3 is the effect of calcination temperature on the average grain size of YSZ nanocrystals without isothermal hold time. As shown in Fig.3, YSZ nanocrystals start to grow at about $300{ }^{\circ} \mathrm{C}$. The grain size of nanocrystals is dependent on the calcination temperature: the higher the calcination temperature, the larger the grain size. Further, according to the shape of grain growth curve, two grain growth regimes can be divided into and at each regime, the grain size increases linearly with the increase of calcination temperature. The first regime is from $300{ }^{\circ} \mathrm{C}$ to $800^{\circ} \mathrm{C}$; at this regime, nanocrystals grow slowly from $8.70 \mathrm{~nm}$ to $17.09 \mathrm{~nm}$ with growth rate of about $1.68 \mathrm{~nm}$ per $100^{\circ} \mathrm{C}$. The second regime is from 800 to $1200^{\circ} \mathrm{C}$; at this regime, the grain growth clearly accelerates; the grain size reaches to about $50 \mathrm{~nm}$ at $1200^{\circ} \mathrm{C}$ with grain growth rate of about $6.58 \mathrm{~nm}$ per $100^{\circ} \mathrm{C}$. The grain growth rate at the second regime is almost four times of that at the first regime.

Fig. 4 shows the effect of calcination temperature of non-isothermal sintering on the grain size distribution of YSZ nanocrystals. Nanocrystals before growing up have narrow grain size distribution with nearly symmetric distribution curve. With the increase of calcination temperature, the grain size distribution becomes broader and broader, showing an increase of distribution width, an increase of asymmetry of distribution curve and a decrease of peak frequency. Moreover, a discontinued disappearance 


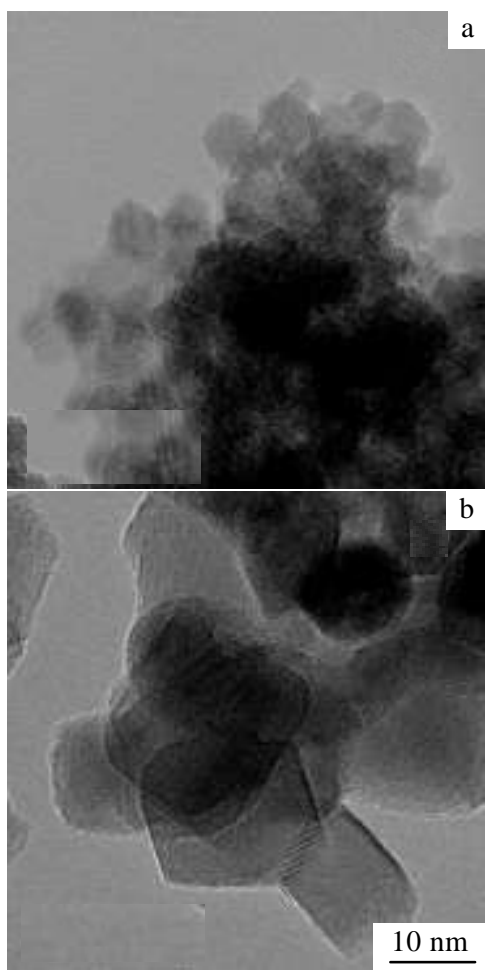

Fig.1 HRTEM images of YSZ nanocrystals calcinated at $300^{\circ} \mathrm{C}$ (a) and $900{ }^{\circ} \mathrm{C}(\mathrm{b})$

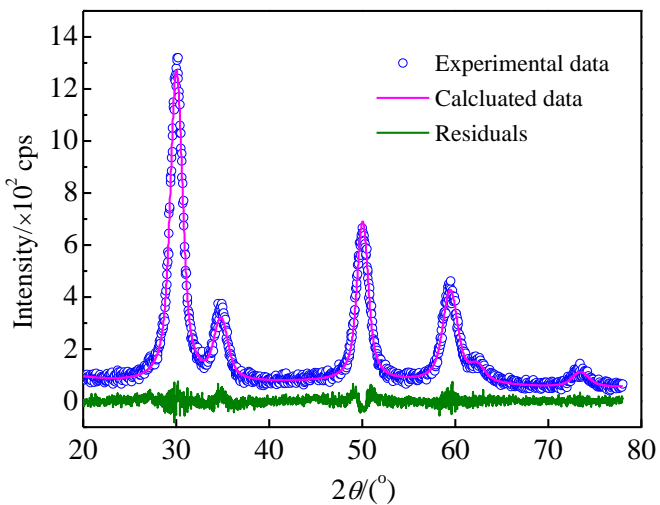

Fig.2 WPPM analysis result for nanocrystals calcinated at $300^{\circ} \mathrm{C}$

of small grains and a discontinued appearance of large grains can be observed between adjacent calcination temperatures.

Grain growth of polycrystalline materials can be empirically described by the equation ${ }^{[26,27]}$ :

$$
D^{n}-D_{0}^{n}=k t
$$

where $D_{0}$ is the initial grain size; $D$ is the grain size at time $t$; $n$ is the grain growth exponent; $k$ is a rate constant which

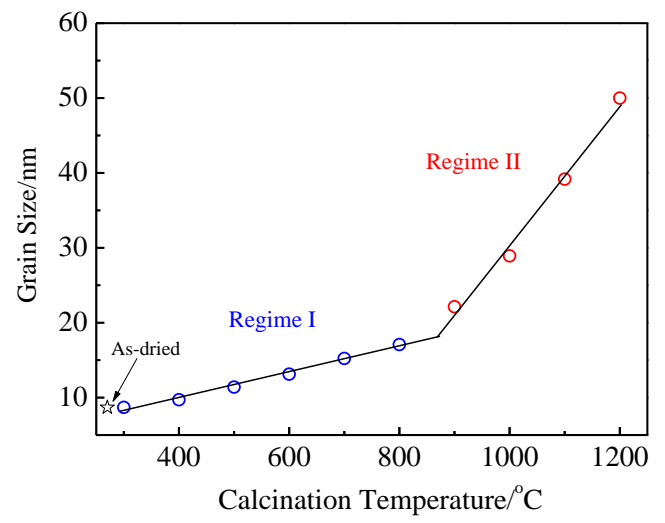

Fig.3 Effect of calcination temperature of non-isothermal sintering on the grain size of YSZ nanocrystals

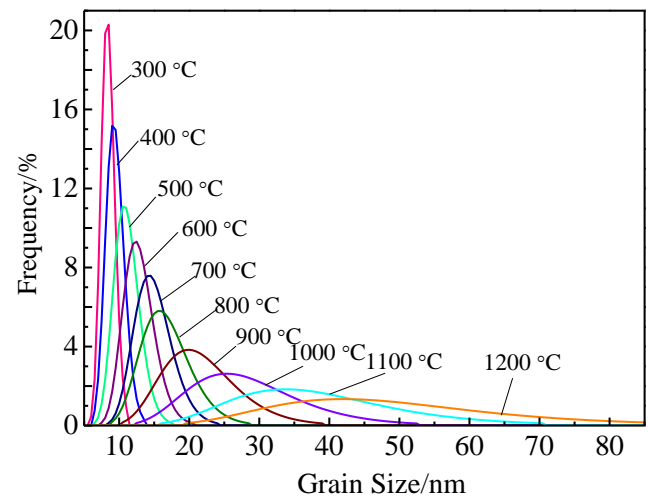

Fig.4 Effect of calcination temperature of non-isothermal sintering on the grain size distribution of YSZ nanocrystals

is a temperature dependent but time independent coefficient; $k$ can be described by the equation ${ }^{[26,27]}$ :

$$
k=k_{0} \mathrm{e}^{-\frac{Q}{R T}}
$$

where $k_{0}$ is the pre-exponential coefficient; $Q$ is the apparent activation energy for grain growth; $R$ is the gas constant; $T$ is the temperature. Because both $T$ and $t$ are changed at the same time during non-isothermal sintering, to evaluate the grain growth exponent as well as the activation energy, Eq.(2) can be rewritten by replacing $t$ with $T$ if a constant heating rate is used during sintering:

$$
D^{n}-D_{0}^{n}=k_{0} \beta T \mathrm{e}^{-\frac{Q}{R T}}
$$

where $\beta$ is the inverse of heating rate; the natural logarithm of both sides of Eq.(4) is:

$$
\ln \left(D^{n}-D_{0}^{n}\right)=-\frac{Q}{R}\left(\frac{1}{T}\right)+\ln \left(k_{0} \beta\right)+\ln (T)
$$


By plotting $\ln \left(D^{n}-D_{0}{ }^{n}\right)-\ln (T)$ vs $1 / T$ in Eq.(5) with different values of $n$, it is found that the data can follow a straight line fit at the two regimes in Fig.3. Thus, linear regression by the least squares method is performed to determine the slope of fitting line for determining the activation energies of grain growth during non-isothermal sintering. The regression fitting coefficients using different grain growth exponents of two regimes are shown in Table 1. From Table 1, it can be seen that $n$ is 6 at regime I and $n$ is 1 at regime II which have the best fit.

Fig.5 shows the plot of $\ln \left(D^{n}-D_{0}{ }^{n}\right)-\ln (T)$ vs $1 / T$ with grain growth exponent of 6 for regime I and grain growth exponent of 1 for regime II. The activation energies determined from the slope of fitting lines of the two regimes are 53.16 and $42.48 \mathrm{~kJ} / \mathrm{mol}$, respectively.

\subsection{Grain growth of isothermal sintering}

Fig. 6 shows the grain size as a function of isothermal hold time at different calcination temperatures. As shown in Fig.6, the grain size of nanocrystals increases with the increase of isothermal hold time but the grain growth rate is dependent on the calcination temperature. Below $800{ }^{\circ} \mathrm{C}$, nanocrystals grow slowly and almost linearly with the increase of isothermal hold time. Above $800^{\circ} \mathrm{C}$, an obvious fast growth of grain size at the first hour of isothermal holding can be observed. When the isothermal holding time is longer than $1 \mathrm{~h}$, the grain growth slows down. Moreover, the grain growth rate at the first hour of isothermal holding is dependent on the calcination temperature: the higher the calcination temperature, the larger the grain growth rate at the first hour during isothermal holding.

Combined with Fig.3 and Fig.6, it can be concluded that, the grain growth of YSZ nanocrystals mainly occurs at the heat-up stage and in the first hour of isothermal holding. Moreover, the influence of calcination temperature on the grain size is more significant than isothermal holding time, especially at temperature above $800{ }^{\circ} \mathrm{C}$.

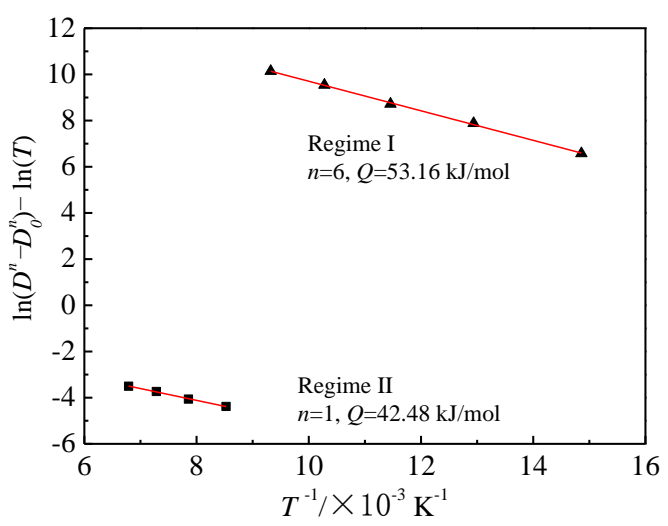

Fig.5 Plots of $\ln \left(D^{n}-D_{0}{ }^{n}\right)-\ln (T)$ vs. $1 / T$ of YSZ nanocrystals at two grain growth regimes

Table 1 Regression fitting coefficient using different grain growth exponent

\begin{tabular}{|c|c|c|c|c|c|c|c|c|c|c|}
\hline$n$ & 1 & 2 & 3 & 4 & 5 & 6 & 7 & 8 & 9 & 10 \\
\hline Regime I & 0.9637 & 0.9810 & 0.9908 & 0.9960 & 0.9984 & 0.9992 & 0.9990 & 0.9985 & 0.9977 & 0.9970 \\
\hline Regime II & 0.9984 & 0.9975 & 0.9966 & 0.9962 & 0.9960 & 0.9960 & 0.9960 & 0.9960 & 0.9960 & 0.9961 \\
\hline
\end{tabular}

To compare the evolution of grain size distribution of YSZ nanocrystals at different temperatures with different isothermal holding time, the coefficient of variation $\left(C_{\mathrm{V}}\right)$ of grain size distribution is calculated from the follow equation in term of the parameters of lognormal distribution function ${ }^{[25]}$.

$$
C_{\mathrm{V}}=\sqrt{e^{\sigma^{2}}-1}
$$

According to the definition of $C_{\mathrm{V}}$, the increase of $C_{\mathrm{V}}$ indicates that the grain size distribution becomes broader. Fig.7 shows the $C_{\mathrm{V}}$ value of grain size distribution of YSZ nanocrystals at different calcination temperatures and with different isothermal holding time. It can be seen from Fig.7 that, $C_{\mathrm{V}}$ increases not only with the increase of calcination temperature, but also with the increase of isothermal holding time. The influence of isothermal holding time on grain size distribution above $700^{\circ} \mathrm{C}$ is more significant than that below $700{ }^{\circ} \mathrm{C}$.

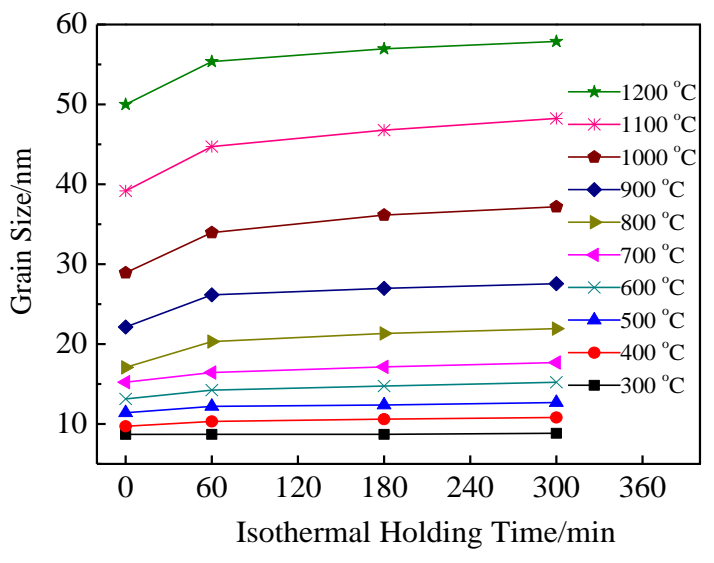

Fig.6 Grain size of nanocrystals as a function of isothermal hold time at different calcination temperatures 


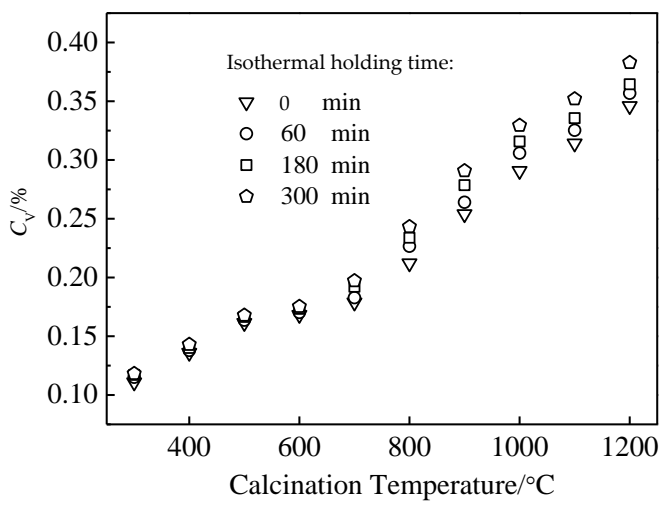

Fig.7 Plot of $C_{\mathrm{V}}$ of grain size distribution of YSZ nanocrystals at different temperatures and with different isothermal hold time

Examples of grain size distribution of YSZ nanocrystals at different calcination temperatures and with different isothermal holding time are shown in Fig.8. The broadening of the grain size distribution of YSZ nanocrystals during isothermal sintering mainly occurs at the first hour of isothermal holding.
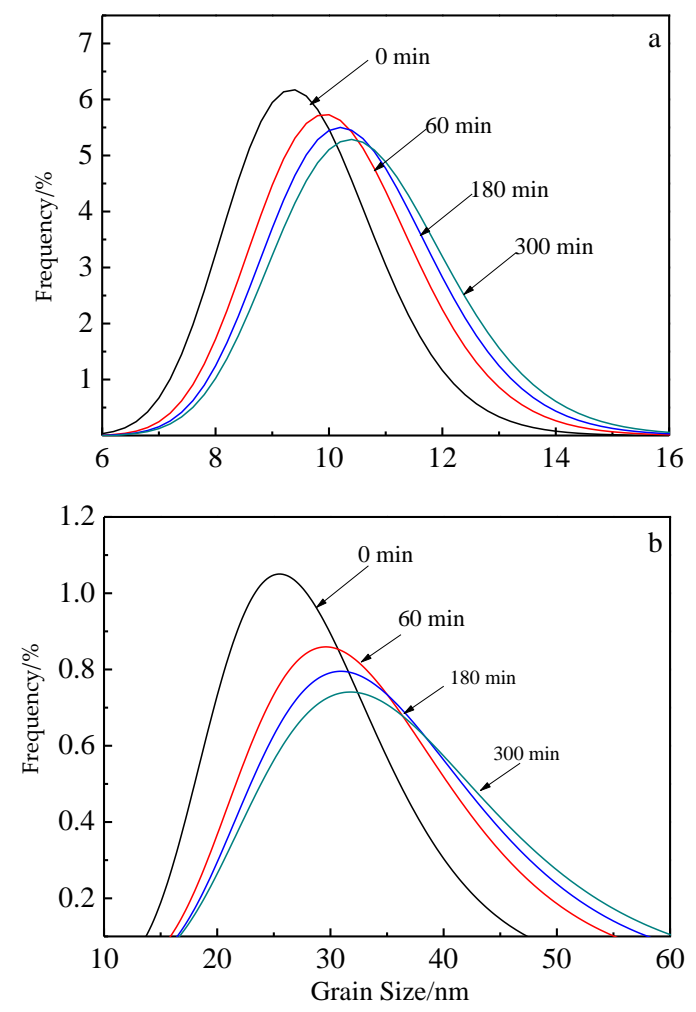

Fig.8 Evolution of grain size distribution of YSZ nanocrystals calcinated at $400{ }^{\circ} \mathrm{C}$ (a) and $1000{ }^{\circ} \mathrm{C}$ (b) for different isothermal holding time
To evaluate the grain growth exponent and the active energy of grain growth of isothermal sintering, the grain size at each calcination temperature without isothermal holding is used as the start grain size $\left(D_{0}\right)$ in Eq.(2). Data of $\left(D^{n}-D_{0}{ }^{n}\right)$ with different $n$ are plotted as a function of isothermal holding time at different temperatures; results show that $n=2$ has the best fit. Fig. 9 is the plot of $\left(D^{2}-\right.$ $D_{0}{ }^{2}$ ) as a function of isothermal holding time at different temperatures. It can be seen from Fig.9 that the data of $\left(D^{2}-D_{0}{ }^{2}\right)$ at different temperatures increases linearly with isothermal holding time but with different slope, i.e. different $k$ in Eq.(2).

Fig. 10 plots the natural logarithm of $k$ with the inverse of calcination temperature, where $k$ is the slope of fitting line at different calcination temperatures in Fig.9. The activation energy derived from the slope of fitting line in Fig.10 is $37.18 \mathrm{~kJ} / \mathrm{mol}$.

\subsection{Grain growth mechanism of YSZ nanocrystals}

Previous studies have shown that grain growth of YSZ microcrystals is a thermally activated diffusional mass transport process at elevated temperatures, usually in the temperature range between 0.5 and $0.8 T_{\mathrm{m}}\left(T_{\mathrm{m}}\right.$ is the melting temperature of YSZ) where diffusional mass transport is appreciable ${ }^{[28]}$. The grain growth exponent of YSZ microcrystals is 3 and the active energy is several hundred kilojoules per mole ${ }^{[29]}$. However, in this study, YSZ nanocrystals start to grow at very low temperature (about $0.14 T_{\mathrm{m}}$ of YSZ). Moreover, the grain growth active energy is obviously lower than that of YSZ microcrystals. Thus, the grain growth mechanism of YSZ nanocrystals is different from that of YSZ microcrystals.

Recent studies proposed a grain growth mechanism of nanocrystals named as grain rotation induced grain coalescence (GRIGC) ${ }^{[30,31]}$. Fig.11 is the hypothetic diagram of GRIGC process between nanocrystals. Nanocrystals can rotate to adjust the orientation to the same

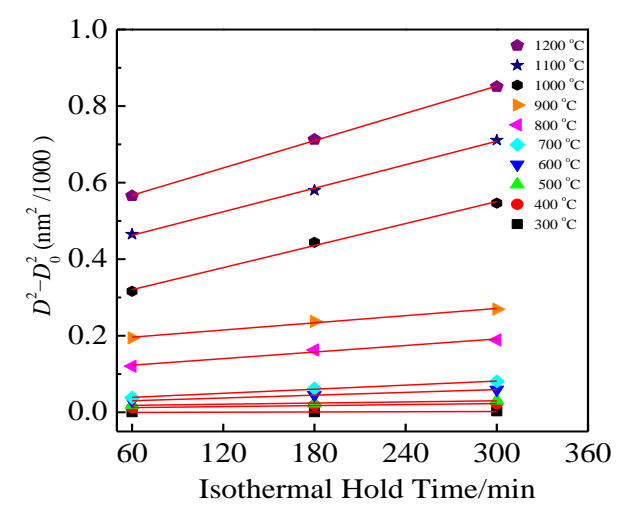

Fig.9 Plot of $\left(D^{2}-D_{0}{ }^{2}\right)$ with isothermal holding time at different temperatures 


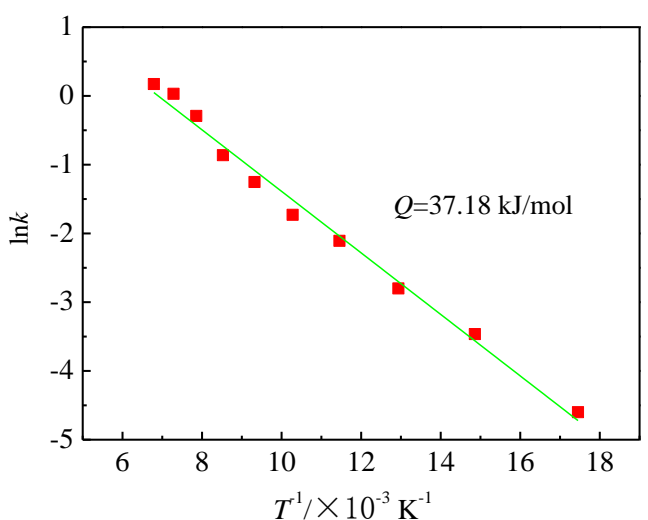

Fig.10 Plot of $\ln k$ with $1 / T$ during isothermal hold

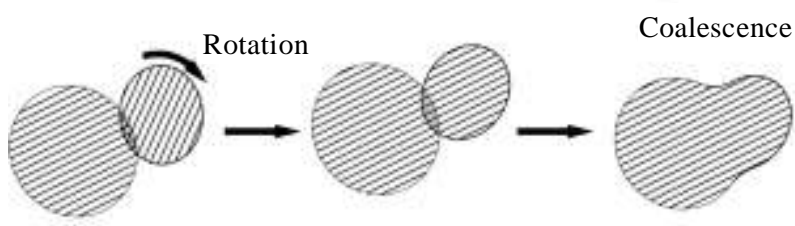

Fig.11 Hypothetic diagram of the coalescence of nanocrystals through GRIGC process

with neighboring grains. The adjacent nanocrystals which have the same orientation can coalesce with each other by eliminating the common grain boundaries. The rotation process has very low activation energy or even a zero-kinetic barrier ${ }^{[32-34]}$; nanocrystals thus can grow at low temperature and the grain growth of nanocrystals has low active energy.

The grain growth of YSZ nanocrystals has low starting temperature and low active energy. Moreover, from Fig.4 and Fig.8, it can be found that, with the increase of calcination temperature or with the increase of isothermal holding time, the small grains disappear discontinuously and the distributions skew to right with a long tail towards large grains at the same time. The discontinuous disappearance of small grains can only come from the coalescence between grains, because grain growth by mass transport between nanocrystals will, on the other hand, bring about an increase of smaller grains due to the mass transport between grains which is always from the smaller to the larger ${ }^{[30,35]}$. Since grain growth through diffusion also likely occurs at elevated temperature, the GRIGC process can be considered as the predominant way of grain growth of YSZ nanocrystals.

\section{Conclusions}

1) YSZ nanocrystals start to grow at $300^{\circ} \mathrm{C}$ and have a fast growth rate during non-isothermal sintering or isothermal holding at above $800^{\circ} \mathrm{C}$.

2) The grain size distribution of YSZ nanocrystals becomes broader with the increase of calcination temperature or isothermal holding time, especially above $800^{\circ} \mathrm{C}$.

3) The active energies of grain growth of non-isothermal sintering are 53.16 and $42.48 \mathrm{~kJ} / \mathrm{mol}$ when the temperature is below and above $800^{\circ} \mathrm{C}$, respectively. The active energy of grain growth of isothermal sintering is $37.18 \mathrm{~kJ} / \mathrm{mol}$.

4) The GRIGC process is considered as the predominant way of grain growth of YSZ nanocrystals.

Acknowledgments: The authors thank Dr. Matteo Leoni (University of Trento, Italy) who provided the access to the WPPM software and the guidance for the analysis.

\section{References}

1 Kelly J R, Denry I. Dental Materials[J], 2008, 24(3): 289

2 Chevalier J. Biomaterials[J], 2006, 27(4): 535

3 Piticescu R R, Monty C, Taloi D et al. Journal of the European Ceramic Society[J], 2001, 21(10-11): 2057

4 Stöver D, Pracht G, Lehmann H, Dietrich M et al. Journal of Thermal Spray Technology[J], 2004, 13(1): 76

$5 \mathrm{Li} \mathrm{F}, \mathrm{Li} \mathrm{Y} \mathrm{H,} \mathrm{Xu} \mathrm{K} \mathrm{W} \mathrm{et} \mathrm{al.} \mathrm{Rare} \mathrm{Metal} \mathrm{Materials} \mathrm{and}$ Engineering [J], 2014, 43(12): 3183 (in Chinese)

6 Trunec M, Chlup Z. Scripta Materialia[J], 2009, 61(1): 56

7 Knöner G, Reimann K, Röwer R et al. PNAS[J], 2003, 100(7): 3870

8 Srdić V V, Winterer M. Journal of the European Ceramic Society[J], 2006, 26(15): 3145

9 Meyers M A, Mishra A, Benson D J. Progress in Materials Science [J], 2006, 51(4): 427

10 Chaim R, Levin M, Shlayer A et al. Advances in Applied Ceramics $[\mathrm{J}], 2008,107(3): 159$

11 Maglia F, Tredici I G, Tamburini U A. Journal of the European Ceramic Society[J], 2013, 33: 1045

12 Wang H T, Fang Z Z, Hwang K S. Metallurgical and Materials Transactions A[J], 2011, 42(11): 3534

13 Bjørk R, Tikare V, Frandsen H L et al. Journal of the American Ceramic Society[J], 2013,96(1): 103

14 Phaniraj M P, Prasad M, Chokshi A H. Materials Science and Engineering $A[\mathrm{~J}], 2007,463(1): 231$

15 Kerber M B, Zehetbauer M J, Schafler E et al. Journal of the Minerals, Metals and Materials Society[J], 2011, 63(7): 61

16 Scardi P, Leoni M. Journal of Applied Crystallography[J], 2006, 39(1): 24

17 Scardi P, Leoni M. ECS Transactions[J], 2006, 3(9): 125

18 Scardi P, Leoni M. Acta Crystallographica Section A: Foundations of Crystallography[J], 2002, 58(2): 190

19 Leoni M, Scardi P. Journal of Applied Crystallography[J], 2004, 37(4): 629

20 Piticescu R R, Monty C, Taloi D et al. Journal of the 
European Ceramic Society[J], 2001, 21(10-11): 2057

21 Dudnik E V. Powder Metallurgy and Metal Ceramics[J], 2009, 48(3-4): 238 Ceramic Society[J], 2004, 87(6): 1133

Leoni M, Confente T. Z Kristallogr[J], 2006, 23(S): 249

Leoni M, Maggio R, Polizzi S et al. Journal of the American Leoni M, Scardi P. Powder Diffraction[J], 1998, 13(4): 210

Fátima V, Fortes M. Scripta Metallurgica[J], 1988, 22(1): 35

Herring C. Journal of Applied Physics[J], 1950, 21(4): 301

Atkinson H. Acta Metallurgica[J], 1988, 36(3): 469

Groza J R. Nanostructured Materials[J], 1999, 12(5): 987

Luo J, Adak S, Stevens R. Journal of Materials Science[J],
1998, 33(22): 5301

30 Moldovan D, Yamakov V, Wolf D et al. Physical Review Letters[J], 2002, 89(20): 20610

31 Moldovan D, Wolf D, Phillpot S et al. Trends in Nanoscale Mechanics[M], Dordrecht: Springer Netherlands,2003: 35

32 Hsu Y W, Yang K H, Yeh S W et al. Journal of Alloys and Compounds [J], 2013,555:82

33 Shi J L, Deguchi Y, Sakabe Y. Journal of Materials Science[J], 2005, 40(21): 5711

34 Ribeiro C, Lee E J, Giraldi T R et al. Journal of Applied Physics[J], 2005, 97(2): 024313

35 Datye A K, Xu Q. Catalysis Today [J], 2006, 111(1-2): 59

\title{
水热法制备纳米氧化锆煅烧过程中晶粒生长特性研究
}

李 飞 ${ }^{1}$, 李雁淮 ${ }^{1}$, 宋忠孝 ${ }^{1}$, 徐可为 ${ }^{1}$, 马大衍 ${ }^{1}$, 高 波 $^{2}$, 崔 红 $^{2}$

(1. 西安交通大学 金属材料强度国家重点实验室, 陕西 西安 710049)

(2. 西安航天复合材料研究所 纳米材料及表面技术工程中心，陕西 西安 710025)

\begin{abstract}
摘 要: 对水热法制备的纳米氧化锆在不同温度和保温时间条件下进行了㷽烧, 采用 X 射线衍射结合全谱模型方法分析了晶粒尺寸和 晶粒尺寸分布的变化。结果表明, 当㷽烧温度在 $300{ }^{\circ} \mathrm{C}$ 时, 纳米氧化锆晶粒开始生长并伴随着晶粒尺寸分布宽化。纳米氧化锆的晶粒 生长速率及晶粒尺寸分布与㷽烧温度和保温时间有关。根据分析结果, 计算了晶粒生长指数和晶粒生长活化能。讨论了晶粒生长机理, 晶粒旋转合并是纳米氧化锆晶粒生长的主要方式。

关键词: 纳米氧化锆; 晶粒生长; 晶粒尺寸分布; 晶粒旋转合并
\end{abstract}

作者简介: 李飞, 男, 1973 年生, 博士生, 西安交通大学金属材料强度国家重点实验室, 陕西 西安 710049, 电话: 029-83607385, E-mail: nanoshanxi@126.com 